\title{
Gender Differences in Prescribing Among Veterans Diagnosed with Posttraumatic Stress Disorder
}

\author{
Nancy C. Bernardy, PhD ${ }^{1,2}$, Brian C. Lund, PharmD, MS ${ }^{3}$, Bruce Alexander, PharmD 4 , \\ Aaron B. Jenkyn, BA ${ }^{7}$, Paula P. Schnurr, $P h D^{1,2}$, and Matthew J. Friedman, MD, $P h D^{1,2}$ \\ ${ }^{1}$ National Center for PTSD, White River Junction VA Medical Center, White River Junction, VT, USA; ${ }^{2}$ The Geisel School of Medicine Dartmouth \\ College, Hanover, NH, USA; ${ }^{3}$ Center for Comprehensive Access \& Delivery Research and Evaluation Veterans Affairs Medical Center, lowa \\ City, IA, USA; ${ }^{4}$ Pharmacy Service, lowa City VA Health Care System, lowa City, IA, USA.
}

\begin{abstract}
OBJECTIVE: The Department of Veterans Affairs (VA) and Department of Defense (DoD) issued a revised posttraumatic stress disorder (PTSD) Clinical Practice Guideline (CPG) in 2010 with specific pharmacotherapy recommendations for evidencebased quality care. The authors examined prescribing frequencies over an 11-year period prior to the release of the new guideline to determine gender differences in pharmacotherapy treatment in veterans with PTSD.
\end{abstract}

METHOD: National administrative VA data from 1999 to 2009 were used to identify veterans with PTSD using ICD-9 codes extracted from inpatient discharges and outpatient clinic visits. Prescribing of antidepressants, antipsychotics and hypnotics was determined for each year using prescription drug files.

RESULTS: Women were more likely than men to receive medication across all classes except prazosin where men had higher prescribing frequency. The proportion of women receiving either of the first-line pharmacotherapy treatments for PTSD, selective serotonin reuptake inhibitors (SSRI) and serotoninnorepinephrine reuptake inhibitors (SNRI), increased from $56.4 \%$ in 1999 to $65.7 \%$ in 2009, higher rates than seen in men (49.2\% to $58.3 \%)$. Atypical antipsychotic prescriptions increased from $14.6 \%$ to $26.3 \%$ and nonbenzodiazepine hypnotics increased from $3.8 \%$ to $16.9 \%$ for women, higher frequencies than seen in men for both medications $(\mathrm{OR}=1.31$, 1.43 respectively). The most notable gender discrepancy was observed for benzodiazepines where prescriptions decreased for men $(36.7 \%$ in 1999 to $29.8 \%$ in 2009) but steadily increased for women from $33.4 \%$ to $38.3 \%$.

CONCLUSION: A consistent pattern of increased prescribing of psychotropic medications among women with PTSD was seen compared to men. Prescribing frequency for benzodiazepines showed a marked gender difference with a steady increase for women despite guideline recommendations against use and a decrease for men. Common co-occurring disorders and sleep symptom management are important factors of PTSD pharmacotherapy and may contribute to gender differences seen in prescribing benzodiazepines in women but do not fully explain the apparent disparity.
KEY WORDS: gender; posttraumatic stress disorder; pharmacology.

J Gen Intern Med 28(Suppl 2):S542-8

DOI: $10.1007 / \mathrm{s} 11606-012-2260-9$

(C) Society of General Internal Medicine 2012

\section{INTRODUCTION}

American women represent a disproportionate number of adults who receive prescriptions for psychotropic medications, with one in four women receiving such medications compared to $15 \%$ of men. ${ }^{1}$ This is particularly true of antianxiety drugs where approximately $11 \%$ of middle-aged American women (ages 45-64) were receiving benzodiazepines in 2010 compared to a rate that was half that seen in comparable-aged men $(5.7 \%) .{ }^{1}$ One possible contributor to the higher prescribing rates is the fact that over their lifetimes women suffer more frequently from psychiatric disorders than men. ${ }^{2}$ Another factor may be that women are also more likely to seek and receive mental health treatment compared to men. ${ }^{3}$ It is not clear if elevated psychiatric medication prescribing among women is solely attributable to greater diagnostic frequency or whether other reasons such as gender differences in acceptance and receipt of mental health treatment may contribute to a significant degree.

VA is committed to identifying and focusing on women veterans' unique health care needs. Women are now the fastest growing cohort within the veteran community and represent approximately $16 \%$ of military personnel who have served in Afghanistan and Iraq. ${ }^{4}$ The rapid growth of women veterans makes it particularly important to examine gender differences in one of the most common diagnoses among veterans seeking care, PTSD. Unfortunately, there are virtually no data concerning prescribing differences across genders in VA, despite the prominent role that pharmacotherapy plays in the management of PTSD. Approximately $60 \%$ of privately insured patients with PTSD receive pharmacotherapy for the disorder, ${ }^{5}$ while close to $80 \%$ of veterans receiving care for PTSD in VA are treated with psychiatric medications. ${ }^{6}$ In the privately insured patients, women were $1 \frac{1}{2}$ times more likely to 
receive psychotropic medications given a PTSD diagnosis than men, but we do not know if this is the case for women veterans treated in the VA. ${ }^{5}$

Given the prominent role that pharmacotherapy has in the management of PTSD, we sought to characterize gender differences in demographic characteristics and psychiatric comorbidity among veterans with PTSD to examine differences in prescribing trends among men and women veterans over an 11-year period (1999-2009) prior to the release of the new VA guideline and to determine the extent to which gender-based differences in prescribing frequencies were explained by demographic and comorbidity variables.

\section{METHODS}

\section{Data Source}

National administrative VA data were obtained for fiscal years 1999 through 2009, including outpatient visit data and inpatient discharge data from the VA Austin Information Technology Center (Austin, TX) and pharmacy data from the VA Pharmacy Benefits Management Services (Hines, IL). Patient-level data were linked between these sources using a scrambled patient identification number. This study was approved by the University of Iowa Institutional Review Board and the Iowa City Veterans Administration Research and Development Committee.

\section{Patients}

Veterans with PTSD were identified using diagnostic codes extracted from inpatient and outpatient clinic visit data. Patients were considered to have PTSD during a given year if they had at least one visit coded for PTSD as either primary or secondary diagnosis. PTSD was identified using the International Classification of Diseases, Ninth Revision (ICD-9) code of 309.81. This case definition has been used in prior work examining medication use in veterans with PTSD. ${ }^{6-9}$ The estimated rate of false-positive cases due to administrative miscoding is infrequent $(<4 \%)$ using this case definition. ${ }^{10,11}$

\section{Medication Use}

Medication use for each patient was based on having at least one outpatient prescription fill of any quantity, days' supply or dosage from within selected therapeutic classes. Medications were selected based on their classification in the VA/DOD CPG for PTSD and prior studies of prescribing practices among veterans with PTSD. ${ }^{6,9,12}$ These classes included selective serotonin reuptake inhib- itors (SSRIs), serotonin-norepinephrine reuptake inhibitors (SNRIs), atypical antipsychotics, benzodiazepines, nonbenzodiazepine hypnotics (included zolpidem, eszopiclone, zaleplon and ramelteon) and prazosin. Prazosin was included in the analysis based on its recommendation in the CPG for targeting symptoms of sleep disturbances and nightmares.

\section{Demographic Characteristics and Psychiatric Comorbidity}

Demographic and psychiatric comorbidity variables were determined during 2009. Demographic variables included gender, age and urban residence. Urban residence was determined according to Rural-urban Commuting Areas. ${ }^{13}$ Military service variables included level of VA serviceconnected disability rating (monetary benefit paid for injury or illness incurred during active military service) and service era, categorized as prior to, during, and post Vietnam era. Time since first PTSD diagnosis was categorized as new, 1-2 year history or $\geq 3$ year history of PTSD in VA. Psychiatric comorbidities were identified by ICD-9 codes using the same case definition as for PTSD, which required at least one clinic visit coded as either primary or secondary diagnosis. The psychiatric comorbidities included in the analysis were depressive disorders, substance use disorders, traumatic brain injury, panic disorder, generalized anxiety disorder, obsessive-compulsive disorder and social phobia.

\section{Statistical Analysis}

Demographic characteristics and psychiatric comorbidity frequencies were compared between men and women using a $t$ test for continuous variables and chi-squared test for categorical variables. Medication prescribing frequencies were reported separately for men and women spanning the study time period of 1999-2009. Temporal changes in gender-based differences in prescribing frequencies were expressed using odds ratios, where values greater than one indicated a higher prescribing frequency for women compared to men.

The influence of demographic characteristics and psychiatric comorbidity on the likelihood of prescribing was examined using multiple logistic regression, with separate analyses conducted for three medication classes commonly prescribed to veterans with PTSD: SSRI/ SNRIs, atypical antipsychotics and benzodiazepines. The first step was to report individual multivariable models for men and women to examine the independent influence of demographic and comorbidity variables on prescribing and contrast effects across gender. Comorbidities were selected for analysis from among DSM-IV Axis I disorders that are 
commonly co-occurring with PTSD or disorders that are valid indications or relative contraindications to benzodiazepine use. The second step was to create four logistic regression models predicting the likelihood of prescribing: (1) gender effect only, (2) gender effect adjusted for demographic variables, (3) gender effect adjusted for comorbidity variables and (4) gender effect adjusted for both demographic and comorbidity variables. Changes in odds ratio for the gender effect across these four models characterized the extent to which gender-based differences in prescribing frequencies were explained by demographic and comorbidity variables. All statistical analyses were conducted using SAS version 9.3 (Cary, NC).

\section{RESULTS}

The number of female veterans being treated for PTSD in the VA health care system tripled during our time frame, from 10,484 in 1999 or $6.2 \%$ of the population to 36,978 in 2009 , which represents $7.5 \%$ of the treated population. Compared to men, women were younger, more likely to have an urban residence, less likely to have a serviceconnected disability greater than $50 \%$ and primarily from the post-Vietnam era (Table 1). Women had higher rates of all comorbidities examined except for substance use disorder and traumatic brain injury.

\section{Gender Differences in Prescribing}

Women with PTSD were more likely to receive medication across all classes except prazosin (Table 2). Prescribing frequency of SSRIs and SNRIs increased for both men and women. Among women, SSRI/SNRI use increased from $56.4 \%$ in 1999 to $65.7 \%$ in 2009. As prescribing also increased in men, the gender ratio for SSRI/SNRIs remained relatively consistent across the 11-year study period, ranging from 1.34 to 1.57 . Gender-based differences, however, were substantial for benzodiazepines. Prescriptions for men decreased over time, consistent with treatment guidelines, but conversely increased over time among women, from $33.4 \%$ in 1999 to $38.3 \%$ in 2009 . Although benzodiazepine prescriptions were less common initially among women than men $(\mathrm{OR}=0.86)$, this pattern reversed such that women were much more likely to receive a benzodiazepine by $2009(\mathrm{OR}=1.47)$. At the beginning of the study period, atypical antipsychotic prescriptions were similar between men and women $(\mathrm{OR}=1.05)$. Rates peaked for both genders in 2005 and decreased thereafter, with higher use ultimately seen among women in 2009 (OR $=1.31$ ). Low-dose quetiapine was examined separately and showed an initial tendency for higher use among women $(\mathrm{OR}=1.88)$, but by 2009 there was no longer any meaningful gender gap in its prescribing $(\mathrm{OR}=1.04)$. Non-benzodiazepine hypnotic prescriptions remained stable in both men and women until zolpidem was placed on the national formulary in 2007, resulting in a tripling of its

Table 1. Gender Differences in Patient Characteristics, FY09

\begin{tabular}{|c|c|c|c|c|}
\hline \multirow[t]{2}{*}{ Characteristic } & All & Women & Men & Statistics \\
\hline & $N=495,309$ & $N=36,978$ & $N=458,331$ & $\chi^{2}$ or t; DF; p \\
\hline \multicolumn{5}{|l|}{ Demographics } \\
\hline Age in years, mean (SD) & $53.8(14.6)$ & $43.3(11.9)$ & $54.7(14.5)$ & $174 ; 46,321 ;<0.0001$ \\
\hline Age group, years & & & & 29,$233 ; 1 ;<0.0001$ \\
\hline$<30$ & $54,343(11.0 \%)$ & $6,535(17.7 \%)$ & $47,808(10.4 \%)$ & \\
\hline $30-39$ & $41,453(8.4 \%)$ & $7,221(19.5 \%)$ & $34,232(7.5 \%)$ & \\
\hline $40-49$ & $52,472(10.6 \%)$ & $10,896(29.5 \%)$ & $41,576(9.1 \%)$ & \\
\hline $50-64$ & $282,451(57.0 \%)$ & $11,409(30.9 \%)$ & $271,042(59.1 \%)$ & \\
\hline$\geq 65$ & $64,590(13.0 \%)$ & $917(2.5 \%)$ & $63,673(13.9 \%)$ & \\
\hline Urban residence & $359,120(73.1 \%)$ & $29,191(79.6 \%)$ & $329,929(72.6 \%)$ & $862 ; 1 ;<0.0001$ \\
\hline Service connection $>50 \%$ & $272,189(55.0 \%)$ & $17,798(46.5 \%)$ & $254,991(55.6 \%)$ & 1,$151 ; 1 ;<0.0001$ \\
\hline \multicolumn{4}{|l|}{ Service era } & 41,$275 ; 1 ;<0.0001$ \\
\hline Pre-Vietnam & $32,477(6.6 \%)$ & $408(1.1 \%)$ & $32,069(7.0 \%)$ & \\
\hline Vietnam & $278,299(56.2 \%)$ & $4,625(12.5 \%)$ & $273,674(59.7 \%)$ & \\
\hline Post-Vietnam & $184,533(37.3 \%)$ & $31,945(86.4 \%)$ & $152,588(33.3 \%)$ & \\
\hline \multicolumn{2}{|l|}{ PTSD $d x$ duration in VA } & & & $644 ; 1 ;<0.0001$ \\
\hline New diagnosis & $109,159(22.0 \%)$ & $9,674(26.2 \%)$ & $99,485(21.7 \%)$ & \\
\hline $1-2$ years & $115,282(23.3 \%)$ & $9,331(25.2 \%)$ & $105,951(23.1 \%)$ & \\
\hline $3+$ years & $270,868(54.7 \%)$ & $17,973(48.6 \%)$ & $252,895(55.2 \%)$ & \\
\hline \multicolumn{5}{|l|}{ Comorbidity } \\
\hline Depressive disorder & $240,920(48.6 \%)$ & $24,257(65.6 \%)$ & $216,663(47.3 \%)$ & $4600 ; 1 ;<0.0001$ \\
\hline Anxiety disorder, any & $39,710(8.0 \%)$ & $5,458(14.8 \%)$ & $34,252(7.5 \%)$ & 2,$464 ; 1 ;<0.0001$ \\
\hline Panic disorder & $19,084(3.9 \%)$ & $3,027(8.2 \%)$ & $16,057(3.5 \%)$ & $2025 ; 1 ;<0.0001$ \\
\hline GAD & $19,719(4.0 \%)$ & $2,303(6.2 \%)$ & $17,416(3.8 \%)$ & $528 ; 1 ;<0.0001$ \\
\hline OCD & $3,809(0.8 \%)$ & $676(1.8 \%)$ & $3,133(0.7 \%)$ & $587 ; 1 ;<0.0001$ \\
\hline Social phobia & $1,388(0.3 \%)$ & $161(0.4 \%)$ & $1,227(0.3 \%)$ & $34 ; 1 ;<0.0001$ \\
\hline Substance use disorder & $111,010(22.4 \%)$ & $6,594(17.8 \%)$ & $104,416(22.8 \%)$ & $482 ; 1 ;<0.0001$ \\
\hline Traumatic brain injury & $21,652(4.4 \%)$ & $1,249(3.4 \%)$ & $20,403(4.5 \%)$ & $94 ; 11 ;<0.0001$ \\
\hline
\end{tabular}


prescribing rate within 2 years. Again, women were consistently receiving significantly more of these prescriptions than men in 2009 (OR = 1.43). Prazosin prescribing was distinct in that prescriptions were consistently lower for women than men, though prazosin use increased in both genders. Notably, the gender gap in prazosin use decreased markedly from an odds ratio of 0.14 in 1999 to 0.75 in 2009.

\section{Independent Predictors of Prescribing}

Demographic characteristics and psychiatric comorbidities were then examined as independent predictors of prescribing for SSRI/SNRIs, benzodiazepines and atypical antipsychotics (Table 3). Age had minimal impact on prescribing for SSRI/SNRIs in either gender but had substantial effect on prescribing of benzodiazepines and atypical antipsychotics. Younger reproductive-age women had lower rates of receipt of both medications. The atypical antipsychotics showed an inverted U-shaped pattern of prescribing where lower rates were seen in younger veterans, increased in middle age and then showed large decreases in the oldest age group in both men and women. An increased percentage of VA service-connected disability $(>50 \%)$ contributed to an increase in prescribing of all medications for both men and women.

Psychiatric comorbidity had significant impact on prescribing. The likelihood of SSRI/SNRI use was nearly three-fold higher among patients with co-occurring depressive disorder. Benzodiazepine use was more common for all anxiety disorder comorbidities, though most dramatically with panic disorder. Elevated prescribing of atypical antipsychotics was observed in both men and women with co-occurring substance use disorder. Traumatic brain injury was associated with increased prescribing across all medication classes, except for SSRI/SNRI use in women. The impact of comorbidity on prescribing was generally consistent across genders. However, a notable exception was benzodiazepine use among veterans with comorbid substance use, which is considered a contraindication according to guideline recommendations. Among women veterans, benzodiazepine use was actually higher for women with co-occurring substance use disorder, whereas the opposite was true for men.

\section{Gender Effects of Demographic Characteristics and Comorbidities}

The impact of demographic characteristics and psychiatric comorbidities on gender-based differences in prescribing is examined in Table 4. Differences in SSRI/SNRI prescribing were largely attributable to differences in comorbidity frequency between genders, as shown by the shift in the gender effect toward a value of one, from an unadjusted odds ratio of 1.37 to 1.13 after adjustment for psychiatric comorbidity. In contrast, adjustment for demographic variables had no effect on the ratio of SSRI/SNRI prescribing across genders. Competing effects were seen for benzodiazepine use, where adjustment for demographic characteristics increased impact of gender, whereas adjustment for comorbidity decreased impact. The net result of simultaneous adjustment for these effects was a persistence in gender-based discrepancy in benzodiazepine prescribing $(\mathrm{OR}=1.47)$ that could not be explained by underlying difference between genders in demographics or psychiatric comorbidities. Finally, gender-based differences in atypical antipsychotic prescribing were primarily attributable to differences in demographic characteristics, reflected by an unadjusted odds ratio of 1.31 to 1.08 after the adjustment for demographics.

\section{DISCUSSION}

The primary objective of this work was to examine gender differences in psychopharmacological prescribing among veterans with PTSD and determine the extent to which these differences may be explained by underlying variation in the frequency of demographic characteristics and comorbid diagnoses. Women veterans with PTSD are more likely to have been recently diagnosed, are younger than men by a decade, have less VA service-connected disability and are primarily post-Vietnam era. Women were more likely to have co-occurring depressive and anxiety disorders, whereas men experienced elevated rates of substance use disorder and traumatic brain injury.

Women veterans were more likely to receive psychotropic medications across all classes except prazosin, which was more likely in men. The substantial increases in prescribing of SSRI/SNRIs in women reflect a positive shift toward evidence-based pharmacological care. This translates to an additional 18,388 women receiving first-line recommended medications for the management of PTSD. When adjusted for psychiatric comorbidities, there are still higher frequencies of SSRI/SNRIs in women. It is possible that there are comorbid disorders not accounted for in our analyses unique to women that contribute to this gender difference such as premenstrual dysphoric disorder. It is also possible known sexual side effects cause men to decline SSRI/SNRIs, and they may represent an undertreated group. In any case, the increased frequency of SSRI/ SNRIs for women with PTSD should be viewed as a positive outcome.

We observed comparable guideline-concordant prescription patterns with atypical antipsychotics with similar gender frequencies until a shift occurred in 2003 that saw an increase for women that stayed elevated compared to 
Table 2. Gender Differences in Temporal Prescribing Trends

\begin{tabular}{|c|c|c|c|c|c|c|}
\hline & FY99 & FY01 & FY03 & FY05 & FY07 & FY09 \\
\hline \multicolumn{7}{|l|}{ SSRI/SNRI } \\
\hline Women & $56.4 \%$ & $62.3 \%$ & $68.4 \%$ & $67.5 \%$ & $66.1 \%$ & $65.7 \%$ \\
\hline Men & $49.2 \%$ & $53.3 \%$ & $58.0 \%$ & $58.9 \%$ & $58.2 \%$ & $58.3 \%$ \\
\hline OR $(95 \% \mathrm{CI})$ & $\begin{array}{l}1.34 \\
(1.28,1.39)\end{array}$ & $\begin{array}{l}1.45 \\
(1.40,1.51)\end{array}$ & $\begin{array}{l}1.57 \\
(1.51,1.62)\end{array}$ & $\begin{array}{l}1.45 \\
(1.41,1.49)\end{array}$ & $\begin{array}{l}1.40 \\
(1.36,1.44)\end{array}$ & $\begin{array}{l}1.37 \\
(1.34,1.40)\end{array}$ \\
\hline \multicolumn{7}{|l|}{ Benzodiazepines } \\
\hline Women & $33.4 \%$ & $36.3 \%$ & $37.3 \%$ & $37.5 \%$ & $39.1 \%$ & $38.3 \%$ \\
\hline Men & $36.7 \%$ & $35.2 \%$ & $33.4 \%$ & $31.7 \%$ & $31.3 \%$ & $29.8 \%$ \\
\hline OR $(95 \% \mathrm{CI})$ & $\begin{array}{l}0.86 \\
(0.83,0.90)\end{array}$ & $\begin{array}{l}1.05 \\
(1.01,1.09)\end{array}$ & $\begin{array}{l}1.18 \\
(1.14,1.23)\end{array}$ & $\begin{array}{l}1.30 \\
(1.26,1.33)\end{array}$ & $\begin{array}{l}1.41 \\
(1.38,1.45)\end{array}$ & $\begin{array}{l}1.47 \\
(1.43,1.50)\end{array}$ \\
\hline \multicolumn{7}{|c|}{ Atypical antipsychotics } \\
\hline Women & $14.6 \%$ & $21.6 \%$ & $27.6 \%$ & $29.0 \%$ & $26.6 \%$ & $26.3 \%$ \\
\hline Men & $14.1 \%$ & $20.1 \%$ & $25.1 \%$ & $25.6 \%$ & $22.5 \%$ & $21.3 \%$ \\
\hline OR $(95 \% \mathrm{CI})$ & $\begin{array}{l}1.05 \\
(0.99,1.11)\end{array}$ & $\begin{array}{l}1.09 \\
(1.05,1.15)\end{array}$ & $\begin{array}{l}1.14 \\
(1.10,1.18)\end{array}$ & $\begin{array}{l}1.19 \\
(1.15,1.22)\end{array}$ & $\begin{array}{l}1.25 \\
(1.22,1.29)\end{array}$ & $\begin{array}{l}1.31 \\
(1.28,1.35)\end{array}$ \\
\hline \multicolumn{7}{|l|}{ Zolpidem } \\
\hline Women & $3.8 \%$ & $5.7 \%$ & $5.6 \%$ & $5.5 \%$ & $6.1 \%$ & $16.9 \%$ \\
\hline Men & $3.8 \%$ & $4.9 \%$ & $4.3 \%$ & $3.9 \%$ & $4.2 \%$ & $12.4 \%$ \\
\hline OR $(95 \%$ CI $)$ & $\begin{array}{l}1.02 \\
(0.92,1.13)\end{array}$ & $\begin{array}{l}1.18 \\
(1.09,1.28)\end{array}$ & $\begin{array}{l}1.33 \\
(1.24,1.43)\end{array}$ & $\begin{array}{l}1.44 \\
(1.35,1.53)\end{array}$ & $\begin{array}{l}1.48 \\
(1.40,1.56)\end{array}$ & $\begin{array}{l}1.43 \\
(1.39,1.48)\end{array}$ \\
\hline \multicolumn{7}{|l|}{ Prazosin } \\
\hline Women & $0.2 \%$ & $0.7 \%$ & $1.9 \%$ & $3.5 \%$ & $5.0 \%$ & $7.1 \%$ \\
\hline Men & $1.5 \%$ & $1.6 \%$ & $2.6 \%$ & $4.8 \%$ & $6.4 \%$ & $9.3 \%$ \\
\hline OR $(95 \% \mathrm{CI})$ & $\begin{array}{l}0.14 \\
(0.09,0.21)\end{array}$ & $\begin{array}{l}0.41 \\
(0.32,0.51)\end{array}$ & $\begin{array}{l}0.73 \\
(0.64,0.82)\end{array}$ & $\begin{array}{l}0.73 \\
(0.67,0.79)\end{array}$ & $\begin{array}{l}0.76 \\
(0.72,0.80)\end{array}$ & $\begin{array}{l}0.75 \\
(0.72,0.78)\end{array}$ \\
\hline
\end{tabular}

those for men. When adjusted for demographic characteristics, there were still elevations in frequency in women that were not accounted for by different prescribing patterns in different age groups and for more severe service-connected disability. It is possible that atypical antipsychotics may be targeted at insomnia symptoms in women as there is evidence of gender differences in arousal symptoms. ${ }^{14}$ However, when we examined low-dose quetiapine separately, no gender differences in prescribing were seen. It is important to note that during this time there were a number of studies suggesting that atypical antipsychotics were effective adjunctive treatments for PTSD, and it is possible again that men were actually undertreated rather than overuse seen in women.

Prescribing frequencies for benzodiazepines were the significant exception. As opposed to decreased prescribing for men, which is guideline-concordance practice, prescriptions steadily increased for women despite recommendations in the CPG against their use in PTSD because of safety and efficacy concerns. Chronic use of benzodiazepines can cause cognitive problems, increase the risk of falls and accidents and have possible detrimental effects on the recommended psychotherapies for PTSD. With their abuse and dependence properties, benzodiazepines are contraindicated in those with comorbid substance use disorder in patients with PTSD $^{15}$ as well as contraindicated in those with TBI. ${ }^{12}$ Not only did we find increased rates of prescribing in women, but in women with co-occurring substance use disorder, rates of benzodiazepine prescriptions were elevated compared to men, a practice discouraged in the CPG and one previously noted in a smaller sample. ${ }^{17}$ Similarly, elevated benzodiazepine prescriptions were seen in both men and women with TBI, again a contraindicated practice. The impact of adjustment for demographic characteristics and psychiatric comorbidities on benzodiazepines was not straightforward. Some increased frequency of prescriptions for benzodiazepines in women is clearly accounted for by comorbidities and again may be related to co-occurring disorders that were not controlled for in our analyses. However, demographic differences also are influential, and age is one such factor. Reduced prescribing of benzodiazepines in the youngest reproductive-age group of women when contrasted to their male counterparts is encouraging. Being older and having a greater service-connected disability contributed to elevated benzodiazepine prescribing. It is possible high rates of distress seen in newly returning veterans from the wars in Iraq and Afghanistan may be a reason for an increase in benzodiazepine prescribing. ${ }^{16,17}$ It is also possible that clinicians prescribe benzodiazepines to women for symptoms that are not an indication for their use, including headache, fatigue, chest pain and vertigo. ${ }^{18}$

Sleep symptom management clearly plays a prominent role in PTSD pharmacotherapy. It is possible that increased prescribing of atypical antipsychotics and benzodiazepines in women is an attempt to address insomnia symptoms. We are unable to capture insomnia symptoms associated with PTSD using administrative data but think that it is important that this be examined in future work. The extraordinary $10 \%$ increase in zolpidem use in women from 2007 to 2009 after the drug became available on formulary confirms how much sleep difficulties are part of the clinical presentation of PTSD. It is not clear why this medication increased so much in women compared to men nor why prazosin would be the exception and more widely used in men. The increased use of nonbenzodiazepine hypnotics does not necessarily reflect a considerably safer 
Table 3. Demographic Characteristics and Psychiatric Comorbidity as Independent Predictors of Prescribing, Multivariable Logistic Regression, FY09

\begin{tabular}{|c|c|c|c|c|c|c|}
\hline \multirow[t]{3}{*}{ Diagnosis } & \multicolumn{2}{|l|}{ SSRI/SNRI } & \multicolumn{2}{|l|}{ Benzodiazepine } & \multicolumn{2}{|c|}{ Atypical antipsychotics } \\
\hline & Women & Men & Women & Men & Women & Men \\
\hline & OR (95\% CI) & OR $(95 \%$ CI $)$ & OR (95 \% CI) & OR (95\% CI) & OR (95\% CI) & OR $(95 \% \mathrm{CI})$ \\
\hline \multicolumn{7}{|l|}{ Demographics } \\
\hline \multicolumn{7}{|l|}{ Age group, years } \\
\hline$<30$ & $\begin{array}{l}0.80 \\
(0.75,0.86)\end{array}$ & $\begin{array}{l}0.85 \\
(0.82,0.87)\end{array}$ & $\begin{array}{l}0.59 \\
(0.55,0.64)\end{array}$ & $\begin{array}{l}0.78 \\
(0.75,0.80)\end{array}$ & $\begin{array}{l}0.58 \\
(0.54,0.63)\end{array}$ & $\begin{array}{l}0.66 \\
(0.64,0.69)\end{array}$ \\
\hline $30-39$ & $\begin{array}{l}0.96 \\
(0.89,1.02)\end{array}$ & $\begin{array}{l}1.01 \\
(0.98,1.04)\end{array}$ & $\begin{array}{l}0.78 \\
(0.73,0.83)\end{array}$ & $\begin{array}{l}0.93 \\
(0.90,0.96)\end{array}$ & $\begin{array}{l}0.81 \\
(0.75,0.87)\end{array}$ & $\begin{array}{l}0.89 \\
(0.86,0.92)\end{array}$ \\
\hline $40-49$ & Reference & Reference & Reference & Reference & Reference & Reference \\
\hline $50-64$ & $\begin{array}{l}1.02 \\
(0.96,1.09)\end{array}$ & $\begin{array}{l}0.96 \\
(0.93,0.99)\end{array}$ & $\begin{array}{l}1.01 \\
(0.95,1.07)\end{array}$ & $\begin{array}{l}1.00 \\
(0.96,1.03)\end{array}$ & $\begin{array}{l}0.85 \\
(0.79,0.90)\end{array}$ & $\begin{array}{l}0.87 \\
(0.84,0.90)\end{array}$ \\
\hline$\geq 65$ & $\begin{array}{l}0.88 \\
(0.72,1.06)\end{array}$ & $\begin{array}{l}0.85 \\
(0.81,0.88)\end{array}$ & $\begin{array}{l}0.84 \\
(0.70,1.01)\end{array}$ & $\begin{array}{l}0.86 \\
(0.83,0.90)\end{array}$ & $\begin{array}{l}0.36 \\
(0.28,0.47)\end{array}$ & $\begin{array}{l}0.59 \\
(0.57,0.62)\end{array}$ \\
\hline Urban residence & $\begin{array}{l}0.90 \\
(0.85,0.95)\end{array}$ & $\begin{array}{l}0.88 \\
(0.86,0.89)\end{array}$ & $\begin{array}{l}0.90 \\
(0.85,0.95)\end{array}$ & $\begin{array}{l}0.86 \\
(0.84,0.87)\end{array}$ & $\begin{array}{l}0.94 \\
(0.88,0.99)\end{array}$ & $\begin{array}{l}0.95 \\
(0.94,0.97)\end{array}$ \\
\hline Service connection >50\% & $\begin{array}{l}1.26 \\
(1.20,1.32)\end{array}$ & $\begin{array}{l}1.29 \\
(1.27,1.31)\end{array}$ & $\begin{array}{l}1.47 \\
(1.40,1.54)\end{array}$ & $\begin{array}{l}1.46 \\
(1.43,1.48)\end{array}$ & $\begin{array}{l}1.28 \\
(1.22,1.35)\end{array}$ & $\begin{array}{l}1.19 \\
(1.17,1.21)\end{array}$ \\
\hline \multicolumn{7}{|l|}{ Service era } \\
\hline Pre-Vietnam & $\begin{array}{l}0.70 \\
(0.54,0.92)\end{array}$ & $\begin{array}{l}0.80 \\
(0.77,0.82)\end{array}$ & $\begin{array}{l}0.92 \\
(0.71,1.20)\end{array}$ & $\begin{array}{c}1.07 \\
(1.03,1.11)\end{array}$ & $\begin{array}{l}0.98 \\
(0.68,1.42)\end{array}$ & $\begin{array}{l}0.80 \\
(0.77,0.84)\end{array}$ \\
\hline Vietnam & Reference & Reference & Reference & Reference & Reference & Reference \\
\hline Post-Vietnam & $\begin{array}{l}0.89 \\
(0.82,0.97)\end{array}$ & $\begin{array}{l}1.00 \\
(0.98,1.03)\end{array}$ & $\begin{array}{l}0.82 \\
(0.76,0.89)\end{array}$ & $\begin{array}{l}0.92 \\
(0.90,0.95)\end{array}$ & $\begin{array}{l}0.96 \\
(0.88,1.04)\end{array}$ & $\begin{array}{l}1.32 \\
(1.28,1.36)\end{array}$ \\
\hline \multicolumn{7}{|l|}{ PTSD $d x$ duration in VA } \\
\hline New diagnosis & $\begin{array}{l}0.76 \\
(0.71,0.80)\end{array}$ & $\begin{array}{l}0.69 \\
(0.68,0.70)\end{array}$ & $\begin{array}{l}0.63 \\
(0.59,0.67)\end{array}$ & $\begin{array}{l}0.53 \\
(0.52,0.54)\end{array}$ & $\begin{array}{l}0.58 \\
(0.54,0.62)\end{array}$ & $\begin{array}{l}0.47 \\
(0.46,0.48)\end{array}$ \\
\hline $1-2$ years & $\begin{array}{l}1.06 \\
(1.00,1.13)\end{array}$ & $\begin{array}{l}0.98 \\
(0.96,0.99)\end{array}$ & $\begin{array}{l}0.80 \\
(0.76,0.85)\end{array}$ & $\begin{array}{l}0.73 \\
(0.72,0.74)\end{array}$ & $\begin{array}{l}0.84 \\
(0.79,0.89)\end{array}$ & $\begin{array}{l}0.70 \\
(0.69,0.72)\end{array}$ \\
\hline $3+$ years & Reference & Reference & Reference & Reference & Reference & Reference \\
\hline \multicolumn{7}{|l|}{ Comorbidity } \\
\hline Depressive disorder & $\begin{array}{l}2.88 \\
(2.75,3.01)\end{array}$ & $\begin{array}{l}2.61 \\
(2.58,2.64)\end{array}$ & $\begin{array}{l}1.36 \\
(1.30,1.42)\end{array}$ & $\begin{array}{l}1.41 \\
(1.39,1.43)\end{array}$ & $\begin{array}{l}1.04 \\
(0.99,1.10)\end{array}$ & $\begin{array}{l}1.43 \\
(1.41,1.45)\end{array}$ \\
\hline Panic disorder & $\begin{array}{l}1.72 \\
(1.57,1.89)\end{array}$ & $\begin{array}{l}1.71 \\
(1.65,1.77)\end{array}$ & $\begin{array}{l}3.48 \\
(3.21,3.78)\end{array}$ & $\begin{array}{l}4.51 \\
(4.36,4.67)\end{array}$ & $\begin{array}{l}1.31 \\
(1.21,1.42)\end{array}$ & $\begin{array}{l}1.55 \\
(1.50,1.61)\end{array}$ \\
\hline GAD & $\begin{array}{l}1.31 \\
(1.19,1.45)\end{array}$ & $\begin{array}{l}1.41 \\
(1.36,1.46)\end{array}$ & $\begin{array}{l}1.92 \\
(1.75,2.10)\end{array}$ & $\begin{array}{l}2.46 \\
(2.38,2.54)\end{array}$ & $\begin{array}{l}1.12 \\
(1.02,1.24)\end{array}$ & $\begin{array}{l}1.30 \\
(1.26,1.35)\end{array}$ \\
\hline OCD & $\begin{array}{l}1.65 \\
(1.37,1.99)\end{array}$ & $\begin{array}{l}1.88 \\
(1.72,2.05)\end{array}$ & $\begin{array}{l}1.53 \\
(1.30,1.80)\end{array}$ & $\begin{array}{l}1.62 \\
(1.50,1.74)\end{array}$ & $\begin{array}{l}2.14 \\
(1.82,2.51)\end{array}$ & $\begin{array}{l}2.29 \\
(2.12,2.46)\end{array}$ \\
\hline Social phobia & $\begin{array}{l}1.44 \\
(0.97,2.13)\end{array}$ & $(1.40,1.84)$ & $\begin{array}{l}1.30 \\
(0.93,1.81)\end{array}$ & $\begin{array}{l}1.58 \\
(1.40,1.78)\end{array}$ & $\begin{array}{l}1.20 \\
(0.85,1.70)\end{array}$ & $\begin{array}{l}1.34 \\
(1.19,1.52)\end{array}$ \\
\hline Substance use disorder & $\begin{array}{l}1.29 \\
(1.22,1.37)\end{array}$ & $\begin{array}{l}1.10 \\
(1.08,1.11)\end{array}$ & $\begin{array}{l}1.11 \\
(1.05,1.18)\end{array}$ & $\begin{array}{l}0.92 \\
(0.90,0.93)\end{array}$ & $\begin{array}{l}2.71 \\
(2.56,2.87)\end{array}$ & $\begin{array}{l}1.92 \\
(1.89,1.95)\end{array}$ \\
\hline Traumatic brain injury & $\begin{array}{l}1.00 \\
(0.88,1.13)\end{array}$ & $\begin{array}{l}1.16 \\
(1.12,1.20)\end{array}$ & $\begin{array}{l}1.23 \\
(1.09,1.39)\end{array}$ & $\begin{array}{l}1.32 \\
(1.27,1.36)\end{array}$ & $\begin{array}{l}1.14 \\
(1.00,1.30)\end{array}$ & $\begin{array}{l}1.21 \\
(1.17,1.25)\end{array}$ \\
\hline
\end{tabular}

Each column is a separate multiple logistic regression model

alternative to benzodiazepines. Safety concerns in nonbenzodiazepine hypnotics have been noted with elevated hazards of dying compared to those prescribed no hypnotics. ${ }^{19}$ It is imperative that if these patterns reflect an attempt to assist with sleep symptom management that different treatment approaches be considered that include cognitive behavioral therapy for insomnia (CBT-I) and safer medication options.

Table 4. Impact of Adjustment for Demographic Characteristics and Psychiatric Comorbidity on Gender-Based Differences in Prescribing, Multivariable Logistic Regression, FY09

\begin{tabular}{|c|c|c|c|c|c|c|}
\hline \multirow{3}{*}{$\begin{array}{l}\text { Model } \\
\text { Unadjusted }\end{array}$} & \multirow{2}{*}{\multicolumn{2}{|c|}{$\begin{array}{l}\text { SSRI/SNRI } \\
\text { OR }(95 \% \text { CI })^{*} \text { c statistic }\end{array}$}} & \multirow{2}{*}{\multicolumn{2}{|c|}{$\begin{array}{l}\text { Benzodiazepine } \\
\text { OR }(95 \% \text { CI) c statistic }\end{array}$}} & \multirow{2}{*}{\multicolumn{2}{|c|}{$\begin{array}{l}\text { Atypical antipsychotics } \\
\text { OR (95\% CI) c statistic }\end{array}$}} \\
\hline & & & & & & \\
\hline & $\begin{array}{l}1.37 \\
(1.34,1.40)\end{array}$ & 0.511 & $\begin{array}{l}1.47 \\
(1.43,1.50)\end{array}$ & 0.514 & $\begin{array}{l}1.31 \\
(1.28,1.35)\end{array}$ & 0.510 \\
\hline Demographics only & $\begin{array}{l}1.34 \\
(1.31,1.37)\end{array}$ & 0.567 & $\begin{array}{l}1.63 \\
(1.60,1.67)\end{array}$ & 0.608 & $\begin{array}{l}1.08 \\
(1.05,1.10)\end{array}$ & 0.605 \\
\hline Comorbidity only & $\begin{array}{l}1.13 \\
(1.10,1.15)\end{array}$ & 0.630 & $\begin{array}{l}1.27 \\
(1.24,1.30)\end{array}$ & 0.590 & $\begin{array}{l}1.25 \\
(1.22,1.28)\end{array}$ & 0.607 \\
\hline Demographics and comorbidity & $\begin{array}{l}1.15 \\
(1.12,1.18)\end{array}$ & 0.658 & $\begin{array}{l}1.47 \\
(1.44,1.51)\end{array}$ & 0.653 & $\begin{array}{l}1.08 \\
(1.05,1.11)\end{array}$ & 0.652 \\
\hline
\end{tabular}


This study has several limitations. The use of administrative data allows us to describe prescribing trends among veterans with PTSD and to determine predictors of prescribing but does not allow us to fully determine the justifications for the prescribed medications. While we were able to determine rates of comorbid disorders using administrative data, it is difficult to confirm their accuracy, and there are other co-occurring disorders that may be relevant that were not captured. Nor can we confirm the timing (e.g., current active problem as in the case of a cooccurring SUD or distant history) or severity of the cooccurring disorders examined. It is also possible that there may be gender-specific coding biases.

This work highlights important findings regarding gender and PTSD that speak to the need for additional work in several areas. We found differences between men and women that are not explained by comorbidities, especially in the area of prescribing of benzodiazepines. It is encouraging to see prescriptions written for first-line pharmacotherapy treatments for women with PTSD. Reduced benzodiazepine findings in men are also encouraging, but we are left with more questions than we have answers regarding the increased prescribing frequency of benzodiazepines in women. It is still possible that the observed gender differences in prescribing are for what might be considered "appropriate reasons" that take into account other co-occurring disorders or that they reflect a greater willingness among women toward taking medications for mental health problems rather than decision making among prescribers. It is also possible the complexity of these patients may cause clinicians to respond to treatment failures by indiscriminately trying different medications. VA has an opportunity to develop policies and interventions that will improve the care that women veterans returning from war receive for PTSD and decrease the heavy burden of greater comorbid mental health disorders, particularly in the treatment of SUD and TBI. Provider education is sorely needed for this primarily reproductive-aged cohort to inform clinicians about gender differences in side effects, medication dosing and particularly about sex differences in pharmacokinetics of psychotropic medications in order to provide access to quality PTSD care for our veteran women.

Acknowledgments: This project was supported by the Mental Health QUERI, Department of Veterans Affairs (MH-QUERI) (RRP 11-001). Dr. Lund received additional support from the VA Health Services Research and Development Service (CDA 10-017; REA 09220). None of these sponsors had any role in the study design, methods, analyses and interpretation, or in preparation of the manuscript and the decision to submit it for publication. The views expressed in this article are those of the authors and do not necessarily reflect the position or policy of the Department of Veterans Affairs.

Conflict of Interest: The authors declare that they do not have a conflict of interest.
Corresponding Author: Nancy C. Bernardy, PhD; National Center for PTSD, White River Junction VA Medical Center, 215 North Main, White River Junction, VT 05001, USA (e-mail: Nancy.Bernardy@va.gov).

\section{REFERENCES}

1. Muzina DJ, Verbrugge K, Widmer L, Lenzi S, Gravaglia K, Chan A, et al., eds. America's State of Mind-A Decade of Drug Trend and Sex Differences. Women's Health Congress 2012 Annual Meeting; 2012 March 17, 2012; Washington, DC

2. Replication NCS. 12-month prevalence of DSM-IV/WMH-CIDI disorders by sex and cohort 1 http://www.hcp.med.harvard.edu/ncs/ftpdir/ NCS-R_12-month_Prevalence_Estimates.pdf. Accessed October 4, 2012. 2012.

3. Wang PS, Lane M, Olfson M, Pincus HA, Wells KB, Kessler RC. Twelvemonth use of mental health services in the United States: results from the National Comorbidity Survey Replication. Arch Gen Psychiatry. 2005;62(5):629-640.

4. Friedman SA, Phibbs CS, Schmitt SK, Hayes PM, Herrera L, Frayne SM. New women veterans in the VHA: a longitudinal profile. Womens Health Issues. 2011;21(4S):S103-S111.

5. Harpaz-Rotem I, Rosenheck RA, Mohamed S, Desai RA. Pharmacologic treatment of posttraumatic stress disorder among privately insured Americans. Psychiatr Serv. 2008;59(10):1184-1190.

6. Bernardy NC, Lund BC, Alexander BA, Friedman MJ. Prescribing trends in veterans with posttraumatic stress disorder. J Clin Psychiatry. 2012;73(3).

7. Mohamed S, Rosenheck RA. Pharmacotherapy of PTSD in the US Department of Veterans Affairs: diagnostic- and symptom-guided drug selection. J Clin Psychiatry. 2008;69(6):959-965.

8. Harpaz-Rotem I, Rosenheck RA. Tracing the flow of knowledge: geographic variability in the diffusion of prazosin use for the treatment of posttraumatic stress disorder nationally in the Department of Veterans Affairs. Arch Gen Psychiatry. 2009;66 (4):417-421.

9. Lund BC, Bernardy NC, Alexander BA, Friedman MJ. Declining benzodiazepine use in veterans with posttraumatic stress disorder. J Clin Psychiatry. 2012;73(3):292-296. 0160-6689.

10. Gravely AA, Cutting A, Nugent S, Grill J, Carlson KF, Spoont MR. Validity of PTSD diagnoses in VA administrative data: comparison of VA administrative PTSD diagnoses to self-reported PTSD checklist scores. J Rehabil Res Dev. 2011;48(1):21-30.

11. Lund BC, Abrams TE, Gravely AA. Rebuttal to Gravely et al, "Validity of PTSD diagnoses in VA administrative data: comparison of VA administrative PTSD diagnoses to self-reported PTSD Checklist scores" [letter]. J Rehabil Res Dev. 2011;48(5):vii-ix.

12. Department of Veterans Affairs. Post Traumatic Stress Disorder: VA/ DoD Clinical Practice Guideline. 2010. http://www.healthquality.va. gov/Post_Traumatic_Stress_Disorder_PTSD.asp. Accessed October 4, 2012.

13. Agriculture UDo. Rural-urban Commuting Area Codes. http://www. ers.usda.gov/data-products/rural-urban-commuting-area-codes.aspx. Accessed October 4, 2012.

14. Orsillo SM, Raja S, Hammond C. Gender issues in PTSD with comorbid mental health disorders. In: Kimerling R, Ouimette PC, Wolfe J, eds. Gender and PTSD. New York: Guilford Press; 2002:207-231.

15. Lader MH. Benzodiazepines revisited-will we ever learn? Addiction. 2011;106(12):2086-2109.

16. Seal KH, Shi Y, Cohen G, Cohen BE, Maguen S, Krebs EE, et al. Association of mental health disorders with prescription opioids and high-risk opioid use in US veterans of Iraq and Afghanistan. JAMA. 2012;307(9):940-947.

17. Hawkins EJ, Malte CA, Imel ZE, Saxon AJ, Kivlahan DR. Prevalence and trends of benzodiazepine use among Veterans Affairs patients with posttraumatic stress disorder, 2003-3010. Drug Alcohol Depend. 2012;124(1-2):154-161.

18. van der Waals F, Mohrs J, Foets M. Sex differences among recipients of benzodiazepines in Dutch general practice. Br Med J. 1993;307:363-366.

19. Kripke DF, Langer RD, Kline LE. Hypnotics' association with mortality or cancer: a matched cohort study. BMJ Open. 2012;2(e000850). doi:10.1136/bmjopen-2012-000850. 